\title{
ACIDIZATION III-THE KINETICS OF THE DISSOLUTION OF SODIUM AND POTASSIUM FELDSPAR IN HF/HCl ACID MIXTURES
}

\author{
H. S. FOGLER $†$ and K. LUND $\ddagger$ \\ Department of Chemical Engineering, The University of Michigan, Ann Arbor, MI 48104, U.S.A. \\ and \\ C. C. McCUNE \\ Chevron Oil Field Research Company, La Habra, CA 90631, U.S.A.
}

(Received 19 August 1974; accepted 4 April 1975)

\begin{abstract}
The dissolution of a potassium and a sodium feldspar in hydrochloric-hydrofluoric acid mixtures was studied in a rotating disk system at 25 and $100^{\circ} \mathrm{C}$ under a pressure of $40 \mathrm{psig}$. Under these conditions, the dissolution rate is limited by the rate of reaction of the acids with the solid surface.

The rate of dissolution may be described by the following type of rate law:

$$
-r_{\mathrm{A}}=k\left(1+K(\mathrm{HCl})^{a}\right)(\mathrm{HF})^{b} .
$$

The parameters $a$ and $b$ for potassium feldspar have the values 0.4 and 1.2 , respectively, whereas for sodium feldspar both have a value of 1.0 . A mechanism for the dissolution reaction is proposed which is consistent with experimental observation. The analysis suggests that the dissolution is limited by the rate at which the hydrofluoric acid reacts with the solid surface and that the strong influence of the hydrochloric acid on the dissolution rate is due to the adsoption of hydrogen ions on the mineral surface.
\end{abstract}

\section{INTRODUCTION}

Although acidization has been used for many years to increase the productivity of petroleum wells, it has not been thoroughly investigated either experimentally or theoretically to determine to what extent the permeability of the porous formation and the flow capacity of the well will be increased by the acid injection. In the acidization of sandstone formations $\mathrm{HCl} / \mathrm{HF}$ acid mixtures in concentrations of a few percent up to $15 \%$ are injected through the well bore into the porous rock formation thereby enlarging the flow channels and decreasing the resistance to the flow of petroleum.

Sandstone is a granular conglomorate containing a series of different minerals such as silicates and carbonates. The most common silicates present are $\alpha$-quartz, feldspars, and clays. While the dissolution rate of $\alpha$-quartz in hydrofluoric acid has been measured, only qualitative information is available about the dissolution rate of some of the other silicates. Owing to their abundance in sandstone and relatively high reactivity with the acid mixture, the feldspars are expected to play an important part in the processes taking place during acidization. In two previous papers $[1,2]$ the reactions of hydrochloric acid with two common carbonates, calcite and dolomite, were reported.

The reactions of $\mathrm{HCl} / \mathrm{HF}$ acid mixtures with sandstone are quite complex since not only does each mineral react at a different rate but also a series of competing reactions occur between the reactants and reaction products. The most important of these reactions are detailed below.

\footnotetext{
$\dagger$ To whom correspondence should be addressed.
}

$\ddagger$ Present address: Norsk Hydro A/S. Oslo, Norway.

\section{EQUILIBRIUM RELATIONSHIPS}

Hydrofluoric acid [3-5] is a weak acid in dilute solutions

$$
\mathrm{HF} \rightleftarrows \mathrm{H}^{+}+\mathrm{F}^{-} .
$$

The equilibrium constant is

$$
K_{R 1}=\frac{\left(\mathrm{H}^{+}\right)\left(\mathrm{F}^{-}\right)}{(\mathrm{HF})}
$$

In concentrated solutions and in anhydrous hydrogen fluoride, the acidity of hydrofluoric acid is similar to that of strong acids such as sulfuric acid. This behavior is due to the association of $\mathrm{HF}$ and the formation of the strong acids $\mathrm{H}_{i} \mathrm{~F}_{i}$ :

$$
\begin{aligned}
& i \mathrm{HF} \rightleftarrows \mathrm{H}^{+}+\mathrm{H}_{i-1} \mathrm{~F}_{i}^{-} \\
& K_{R i}=\frac{\left(\mathrm{H}^{+}\right)\left(\mathrm{H}_{i-1} \mathrm{~F}_{i}^{-}\right)}{(\mathrm{HF})^{i}}
\end{aligned}
$$

where $K_{R i}$ is the equilibrium constant (in this paper all concentrations are in gmole/ 1 and the value of the equilibrium constants are given for these units of concentration). At $25^{\circ} \mathrm{C}, K_{R 1}=6.6 \times 10^{-4}$ and $K_{R 2}=$ $2.2 \times 10^{-3}$; the values of the higher order equilibrium constants are not known. The concentration of $\mathrm{H}^{+}$in a hydrofluoric acid solution may be found by combining eqn (2) with a mole balance on $\mathrm{H}^{+}$and fluorine:

$$
\begin{aligned}
\left(\mathrm{H}^{+}\right)^{2} & =\sum_{i=1}^{n} K_{R l}(\mathrm{HF})^{i} \\
\left(\mathrm{HF}^{o}\right) & =\sum_{i=1}^{n} i K_{\mathrm{R} i} \frac{(\mathrm{HF})^{i}}{\left(\mathrm{H}^{+}\right)}
\end{aligned}
$$


where $\left(\mathrm{HF}^{\circ}\right)=$ the total amount of hydrofluoric acid present. The values of the equilibrium constants are sufficiently different so that concentration ranges exist where only one of the fluoric acids will determine the acid strength of the solution: For $(\mathrm{HF})<0 \cdot 1$

$$
\left(\mathrm{H}^{+}\right)=\left(K_{R 1}(\mathrm{HF})\right)^{1 / 2}=2.6 \times 10^{-2}(\mathrm{HF})^{1 / 2} \text {. }
$$

For $1 \cdot 5<(\mathrm{HF})<10$

$$
\left(\mathrm{H}^{+}\right)=K_{R 2}^{1 / 2}(\mathrm{HF})=4.7 \times 10^{-2}(\mathrm{HF}) .
$$

Hydrofluoric acid and hydrofluoric-hydrochloric acid mixtures dissolve $\mathrm{SiO}_{2}$ and other silicates by forming highly stable complex fluorides such as fluorosilicates and fluoroaluminates. The dissolution of $\mathrm{SiO}_{2}$ in $\mathrm{HF}-\mathrm{HCl}$ is given by:

$$
\mathrm{SiO}_{2}+4 \mathrm{HF} \rightleftarrows \mathrm{SiF}_{4}+2 \mathrm{H}_{2} \mathrm{O}
$$

and if the solution is in equilibrium with solid $\mathrm{SiO}_{2}$ the equilibrium relationship may be expressed as:

$$
K_{Q 1}=\frac{\left(\mathrm{SiF}_{4}\right)}{(\mathrm{HF})^{4}}
$$

Although $\alpha$-quartz is the thermodynamically stable form of $\mathrm{SiO}_{2}$ at $25^{\circ} \mathrm{C}$ and $1 \mathrm{~atm}$, several other forms of $\mathrm{SiO}_{2}$ such as tridymite, vitreous silica and silica under different degrees of hydration, exist. The value of $K_{Q 1}$ will of course depend on which form of $\mathrm{SiO}_{2}$ is present, and unfortunately only little information is available about it. For hydrated silica formed by precipitation from an aqueous solution, the equilibrium constant has the value at $11^{\circ} \mathrm{C}$ of $K_{Q 1}=1.0 \times 10^{8}$; whereas for $\alpha$-quartz the value is estimated to lie in the range $10^{6}-10^{8}$.

The $\mathrm{SiF}_{4}$ may react further with fluoride ions:

$$
\begin{aligned}
& \mathrm{SiF}_{6}=\mathrm{SiF}_{4}+2 \mathrm{~F}^{-} \\
& K_{\mathrm{Q}^{2}}=\frac{\left(\mathrm{SiF}_{4}\right)\left(\mathrm{F}^{-}\right)^{2}}{\left(\mathrm{SiF}_{6}{ }^{-}\right)}
\end{aligned}
$$

where $K_{Q 2}=0.65 \times 10^{-6}$ at $20^{\circ} \mathrm{C}$.

Another ion, $\mathrm{SiF}_{5}{ }^{-}$, may also be formed in the solution:

$$
\begin{aligned}
& \mathrm{SiF}_{5}^{-} \rightleftarrows \mathrm{SiF}_{4}+\mathrm{F}^{-} \\
& K_{\mathrm{Q}_{3}}=\frac{\left(\mathrm{SiF}_{4}\right)\left(\mathrm{F}^{-}\right)}{\left(\mathrm{SiF}_{5}^{-}\right)} .
\end{aligned}
$$

The equilibria existing between $\mathrm{SiF}_{4}, \mathrm{SiF}_{5}{ }^{-}$, and $\mathrm{SiF}_{6}{ }^{2-}$ have only been investigated [6] in detail in an aqueous solution containing $4 \mathrm{gmole} / 1$ of $\mathrm{LiClO}_{4}$. However, if one assumes that the saturation concentration of $\mathrm{SiO}_{2}$ (hydrated) is only slightly affected by the presence of $\mathrm{LiClO}_{4}$, the value of $\mathrm{K}_{\mathrm{Q} 3}$ at $25^{\circ} \mathrm{C}$ is:

$$
K_{Q 3}=3.8 \times 10^{-6} \text {. }
$$

The equilibria relationships given above allow us to compute the extent of reaction of a $\mathrm{HF} / \mathrm{HCl}$ acid mixture with an excess of silica. For example, when the initial concentration of HF is larger than 0.05 gmole/1 the reaction of $\mathrm{HF}$ with the silica may be considered irreversible, since computation shows that more than $95 \%$ of the hydrofluoric acid will be consumed. The extent of the reaction will be less than $5 \%$ for a hydrofiuoric acid concentration of less than $5 \times 10^{-4}$ gmole $/ 1$.

Except for $\alpha$-quartz, the common silicates in a sandstone will be aluminosilicates. These minerals may contain elements such as $\mathrm{Si}, \mathrm{Al}, \mathrm{Na}, \mathrm{K}, \mathrm{Mg}$ and $\mathrm{Ca}$, and their dissolution stoichiometry will be different from that of $\alpha$-quartz.

The strong tendency of the fluoride ion to be an addend to a central positively charged atom also gives rise, in this case, to a series of equilibria:

$$
\begin{gathered}
\mathrm{AlF}_{i}^{+(3-i)} \rightleftarrows \mathrm{AlF}_{i-1}^{+(4-i)}+\mathrm{F}^{-} ; \quad i=1,2, \ldots, 6 \\
K_{A i}=\frac{\left(\mathrm{AlF}_{i-1}^{+(4-i)}\right)\left(\mathrm{F}^{-}\right)}{\left(\mathrm{AlF}_{i}^{+(3-i)}\right)}
\end{gathered}
$$

where $K_{A l}$, the equilibrium constant, has the values for $i=1,2, \ldots, 6\left(\right.$ at $\left.20^{\circ} \mathrm{C}\right)[3]$ :

$$
\begin{aligned}
& K_{A 1}=7.4 \times 10^{-7} ; K_{A 3}=1.4 \times 10^{-4} ; K_{A 5}=2.4 \times 10^{-2} \\
& K_{A 2}=9.7 \times 10^{-6} ; K_{A 4}=1.8 \times 10^{-3} ; K_{A 6}=0.34
\end{aligned}
$$

The value of the equilibrium constants have been determined for hydrofluoric acid solutions where no hydrochloric acid was present. In hydrochloric/hydrofluoric acid mixtures the hydrochloric acid may effect the value of the equilibrium constants by changing the activity coefficients of the species present and by having $\mathrm{Cl}^{-}$ compete with $\mathrm{F}^{-}$as an addend; both of these effects are judged to be of secondary importance. For the purpose of calculating the ionic composition of the aqueous solution in strong acid solutions it is advantageous to transform the equilibrium relations somewhat:

$$
\begin{gathered}
K_{Q_{3}}^{\prime}=\frac{K_{Q 3}}{K_{R 1}}=5 \cdot 8 \times 10^{-3} \\
K_{Q 4}=\frac{\left(\mathrm{SiF}_{5}^{-}\right)(\mathrm{HF})}{\left(\mathrm{SiF}_{6}^{-}\right)\left(\mathrm{H}^{+}\right)}=\frac{K_{Q 2}}{K_{Q 3} \times K_{R 1}}=260 \\
K_{A i}^{\prime}=\frac{\left(\mathrm{AlF}_{i-1}^{+(4-i)}\right)(\mathrm{HF})}{\left(\mathrm{AlF}_{i}^{+(3-i)}\right)\left(\mathrm{H}^{+}\right)}=\frac{K_{A i}}{K_{R 1}}
\end{gathered}
$$

where

$$
\begin{gathered}
K_{A 1}^{\prime}=9.3 \times 10^{-4} ; K_{A 3}^{\prime}=0.18 ; K_{A 5}^{\prime}=30 \\
K_{A 2}^{\prime}=1.2 \times 10^{-2} ; K_{A 4}^{\prime}=2 \cdot 3 ; K_{A 6}^{\prime}=430
\end{gathered}
$$

In $\mathrm{HCl} / \mathrm{HF}$ mixtures eqns (15), (16) and (17) show the relative distribution of the individual species to be a function only of the $\mathrm{HCl} / \mathrm{HF}$ ratio. For example, in the feldspar dissolution rate experiments performed in this study the $\mathrm{HCl} / \mathrm{HF}$ ratio was varied between 0.03 and 100 . From the above expressions we may compute the average amount of fluoride tied to each atom of dissolved aluminum and silicon at the extremes of this acid ratio: 
for $\mathrm{H}^{+} / \mathrm{HF}=0.03: \quad \mathrm{AlF}_{4.5}, \quad \mathrm{SiF}_{5.1}$

for $\mathrm{H}^{+} / \mathrm{HF}=100: \quad \mathrm{AlF}_{1 \cdot 4}, \quad \mathrm{SiF}_{4 \cdot 6}$.

Although acids other than hydrofluoric cannot dissolve a silicate to any appreciable extent, they may react with aluminosilicates by partial dissolution, thereby changing the mineral into other solid silicates. The type and extent of the reaction is of course not only dictated by the temperature and pressure of the system but also by the concentration of reactants and products in the solution. For example, a potassium feldspar may react with pure water in the following manner[7]:

$$
\mathrm{KAlSi}_{3} \mathrm{O}_{8}+2 \mathrm{H}_{2} \mathrm{O} \rightleftarrows\left(\mathrm{H}_{3} \mathrm{O}\right) \mathrm{AlSi}_{3} \mathrm{O}_{8}+\mathrm{K}^{+}+\mathrm{OH}^{-} \text {. }
$$

Although silica and alumina are only slightly soluble, these compounds may also be dissolved from the aluminosilicates if the solution is not saturated with respect to them. The reaction will be slow because the reactants and products must diffuse through the newly formed solid phase.

\section{EXPERIMENTAL}

Two feldspars in the form of a sodium-feldspar from Bancroft, Ontario and a potassium feldspar from Near Keystone, South Dakota were used in this study [8]. Microscopic examination of thin sections identified the sodium-feldspar as a pure plagioclase with minor unidentified inclusions and the potassium-feldspar as a microcline with a perthitic intergrowth of plagioclase. X-ray diffraction analysis showed the sodium-feldspar to be a pure plagioclase whereas the potassium-feldspar sample was found to be $80 \%$ microcline and $20 \%$ plagioclase. Samples of each of the minerals were dissolved completely in a teflon-lined bomb and the resulting solutions were analyzed by atomic absorption spectroscopy [9].

The compositions found for the two feldspars were:

\section{Potassium-feldspar}

$\left(\mathrm{K}_{0.76} \mathrm{Na}_{0.18} \mathrm{Si}_{0.94}\right)(\mathrm{CaAl})_{0.06} \mathrm{AlSi}_{2} \mathrm{O}_{8}$

\section{Sodium-feldspar}

$\left(\mathrm{Na}_{0.72} \mathrm{~K}_{0 \cdot 08} \mathrm{Si}_{0 \cdot 80}\right)(\mathrm{CaAl})_{0 \cdot 20} \mathrm{AlSi}_{2} \mathrm{O}_{8}$

The chemical analysis of the potassium-feldspar agrees well with the X-ray diffraction analysis. The chemical analysis of the sodium-feldspar identifies it as a potassium oligoclase[10] (a member of the plagioclase series). Density measurement of the two feldspars also supported the results of the chemical analysis.

Disks a quarter inch thick and two inches in diameter ( $1 \frac{1}{2}$ inch in diameter for the sodium-feldspar) were cut from solid mineral samples so that the disk surface would be approximately parallel to either of the two major cleavage planes (with the Miller indices $\{001\}$ and $\{010\}$ ). The faces of the disks were lap polished with 180,320 and 400 mesh carborundum. The $\mathrm{HF}-\mathrm{HCl}$ mixtures were prepared by mixing suitable amounts of concentrated stock solutions of $\mathrm{HF}$ and $\mathrm{HCl}$, and diluting with deionized water. The concentration of the stock solutions was determined by titration with a $0 \cdot 1 N$ sodium hydroxide solution.

The dissolution rate experiments were performed in a rotating disk apparatus. The description of this equipment and the procedure used in performing a dissolution rate experiment have been given previously[1,11]. An $\mathrm{N}_{2}$ pressure of $40 \mathrm{psig}$ was applied to the reacting system. During the course of an experiment 5 to 6 samples of acid were withdrawn from the reactor and analyzed with a Perkin-Elmer Model 303 atomic absorption spectrometer (AAS). The samples were analyzed for $\mathrm{Na}$ (in sodiumfeldspar dissolution experiments) or $\mathrm{K}$ (in potassiumfeldspar experiments), but in many dissolution experiments the samples were analyzed for $\mathrm{Na}, \mathrm{K}, \mathrm{Ca}, \mathrm{Mg}, \mathrm{Al}$ and $\mathrm{Si}$. The ratio of the concentrations of these elements would vary somewhat from sample to sample but averaged around the values given by the chemical formula. Part of this variation is due to the AAS's lesser sensitivity and precision for the elements $\mathrm{Al}$ and $\mathrm{Si}$ as compared with the other elements. The rate of dissolution of the sodium- and potassium-feldspars was computed from the rate of production of $\mathrm{Na}$ and $\mathrm{K}$ respectively. The experimental uncertainty of these rates is estimated to be $\pm 10 \%$.

The reaction stoichiometry for the dissolution of albite or microcline in $\mathrm{HCl}-\mathrm{HF}$ mixtures may be expressed as:

$$
\begin{array}{r}
\mathrm{ZAlSi}_{3} \mathrm{O}_{8}+(n+3 m) \mathrm{HF}+(16-n-3 m) \mathrm{H}^{+} \rightarrow Z^{+} \\
+\mathrm{AlF}_{n}^{+(3-n)}+3 \mathrm{SiF}_{m}^{+(4-m)}+8 \mathrm{H}_{2} \mathrm{O}
\end{array}
$$

where $Z$ indicates either $\mathrm{Na}$ or $\mathrm{K}$. Anorthite will have a slightly different reaction stoichiometry:

$$
\begin{aligned}
\mathrm{CaAl}_{2} \mathrm{Si}_{2} \mathrm{O}_{8} & +(2 n+2 m) \mathrm{HF}+(16-2 \mathrm{n}-2 \mathrm{~m}) \mathrm{H}^{+} \rightarrow \mathrm{Ca}^{2+} \\
& +2 \mathrm{AlF}_{n}^{+(3-n)}+2 \mathrm{SiF}_{m}^{+(4-m)}+8 \mathrm{H}_{2} \mathrm{O}
\end{aligned}
$$

where $n$ and $m$ may take on any real value in the intervals 0 to 6 and 4 to 6 respectively. In these stoichiometric equations $\mathrm{AlF}_{n}^{+(3-n)}$ and $\mathrm{SiF}_{m}{ }^{+(4-m)}$ express the average composition of the series of fluoraluminates and fluorsilicates present in the solution. The two coefficients $n$ and $m$ may be determined by solving the equilibrium relationships eqns (15)-(17), for the actual case in question. The dissolution stoichiometry for the potassium and sodium feldspar used in this investigation may readily be determined by suitable combination of the above expressions. To minimize the change in surface area resulting from uneven attack by the acid on the disk face, the reaction was allowed to proceed only for short periods of time. The final acid consumption was less than $1 \%$. Because the rate of dissolution did change with time owing to the increasing roughness of the disk surface as the experiment progressed, the initial rate of dissolution was used in our analysis.

Rotating disk experiments with the two feldspars [8] were carried out at 25 and $100^{\circ} \mathrm{C}$. The acid mixture concentration was varied from zero to 2.5 gmoles $\mathrm{HF} / \mathrm{l}$ and zero to 5 gmoles $\mathrm{HCl} / 1$. The disk rotation speed range was $100-500 \mathrm{rpm}$. 


\section{DISCUSSION OF RESULTS}

The fluxes of $\mathrm{HF}$ and $\mathrm{HCl}$ to the surface of the rotating feldspar disk were much smaller than those measured for the dissolution of dolomite [1] and calcite [2]. The measured dissolution rate was found to be independent of the disk rotation speed. Consequently, it was concluded that the dissolution of the feldspars at the conditions investigated was limited only by the rate of reaction at the solid surface and not by the diffusive resistance to mass transport. In Figs. 1-4 the dissolution rates of the potassium-feldspar and sodium-feldspar at 25 and $100^{\circ} \mathrm{C}$ are plotted as a function of the hydrofluoric acid concentration. One experiment was performed at $25^{\circ} \mathrm{C}$ with potassium-feldspar in a 3 gmoles/l hydrochloric acid (no HF present) to measure the magnitude of the leaching rate. We note that the measured dissolution rate $\left(r_{\mathrm{K}^{+}}=7.0 \times 10^{-12}\right.$ gmoles $\left.\mathrm{K}^{+} / \mathrm{cm}^{2} / \mathrm{sec}\right)$ is considerably smaller (about 20 times) than the one measured for the

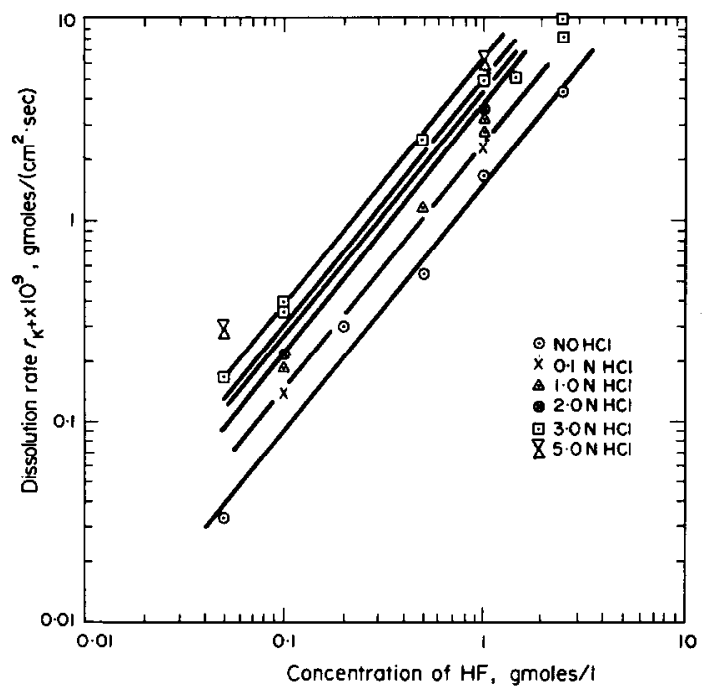

Fig. 1. Dissolution rate of $\mathrm{K}$-feldspar at $25^{\circ} \mathrm{C}$ in $\mathrm{HCl}$-HF mixtures.

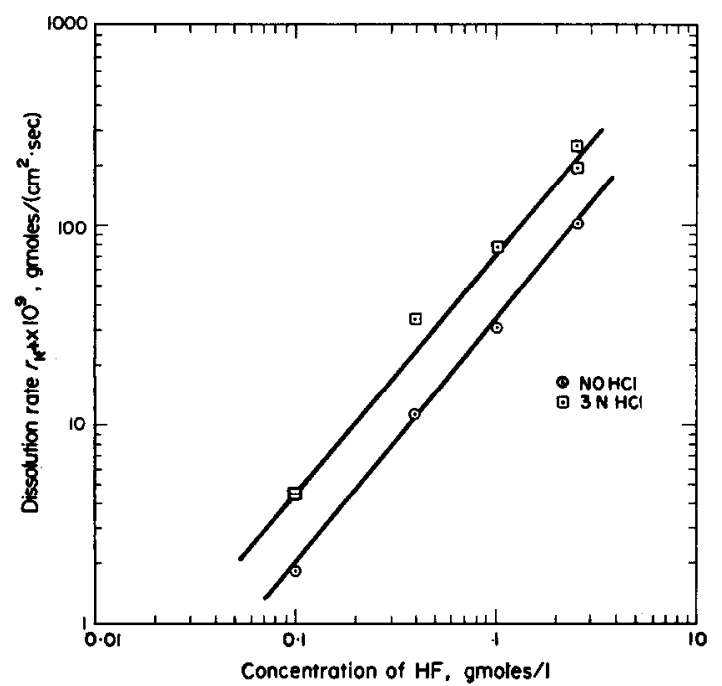

Fig. 2. Dissolution rate of $\mathrm{K}$-feldspar at $100^{\circ} \mathrm{C}$ in $\mathrm{HCl}-\mathrm{HF}$ mixtures.

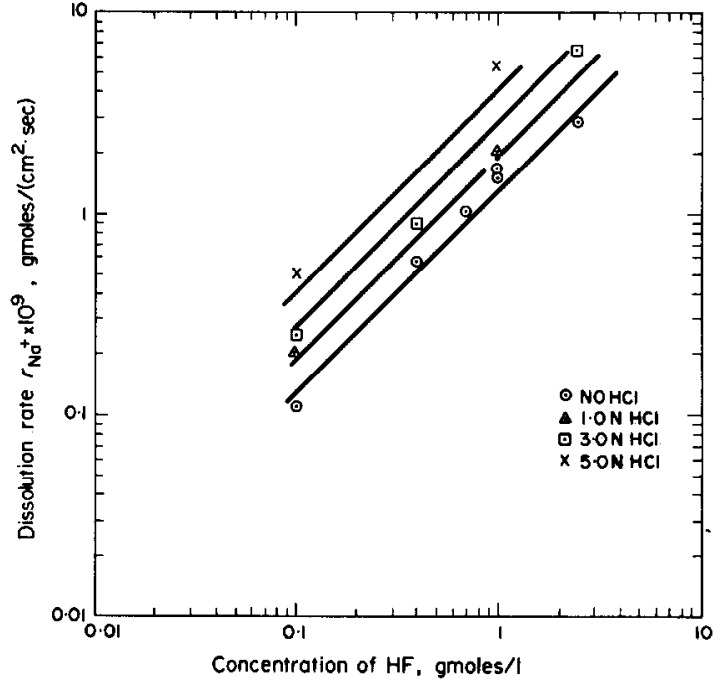

Fig. 3. Dissolution rate of Na-feldspar at $25^{\circ} \mathrm{C}$ in $\mathrm{HCl}-\mathrm{HF}$ mixtures.

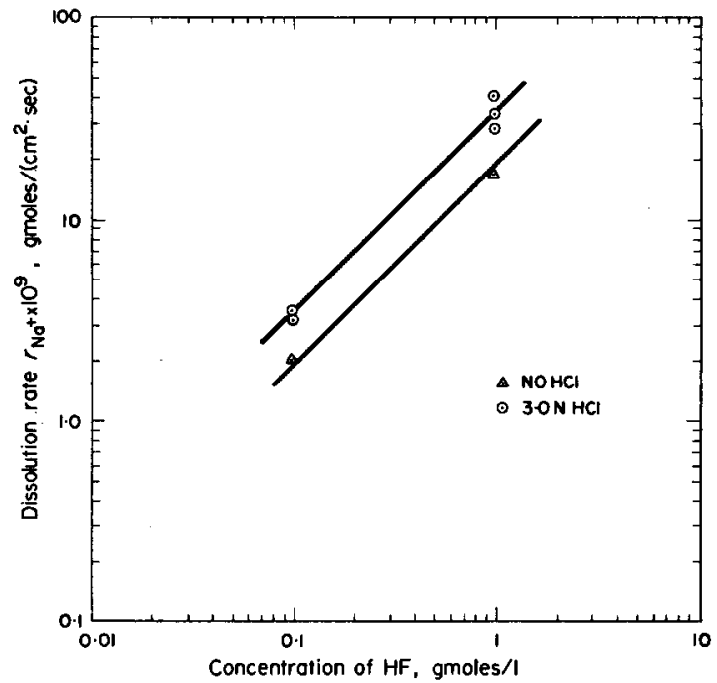

Fig. 4. Dissolution rate of Na-feldspar at $100^{\circ} \mathrm{C}$ in $\mathrm{HCl}-\mathrm{HF}$ mixtures.

0.05 gmoles $\mathrm{HF} / 1$ and 3.0 gmoles $\mathrm{HCl} / 1$ acid mixture; therefore it is reasonable to assume the leaching rate to be negligible.

The addition of hydrochloric acid to the HF acid solution increases the dissolution rate substantially. For a constant hydrochloric acid concentration the percent increase in the dissolution rate is independent of the hydrofluoric acid concentration. This dependency of the dissolution rate suggests that the rate expressions will be separable functions of the hydrofluoric and hydrochloric acid concentrations. The following rate expression was found to describe the dissolution rate of potassiumfeldspar and sodium-feldspar at 25 and $100^{\circ} \mathrm{C}$.

$$
r_{x}=k\left(1+K(\mathrm{HCl})^{a}\right)(\mathrm{HF})^{b}
$$

where $r_{x}$ is the rate of production of species $x$ (e.g. $x=\mathrm{K}^{+}$) in gmoles $x / \mathrm{cm}^{2} / \mathrm{sec}$ and $(\mathrm{HCl})$ and $(\mathrm{HF})$ are the 
concentrations of hydrochloric and hydrofluoric acid in gmoles/1.

For the potassium-feldspar, the dissolution parameters have the values:

$$
a=0.4 ; b=1 \cdot 2 \text {. }
$$

If the rate, $r_{K^{+}}$, has the units gmoles $\mathrm{K}^{+} / \mathrm{cm}^{2} / \mathrm{sec}$, the specific reaction rates have the values:

$$
\begin{aligned}
& \text { at } 25^{\circ} \mathrm{C}: k=1.46 \times 10^{-9} ; K=1.4 \\
& \text { at } 100^{\circ} \mathrm{C}: k=3.4 \times 10^{-8} ; \quad K=0.7
\end{aligned}
$$

The apparent activation energies for $k$ and $K$ are 9.3 and $-1.9 \mathrm{kcal} / \mathrm{gmole}$.

For the sodium-feldspar the parameters have the values:

$$
a=1 \cdot 0 ; b=1 \cdot 0
$$

If the rate, $r_{\mathrm{Na}^{+}}$, has the units gmoles $\mathrm{Na}^{+} / \mathrm{cm}^{2} / \mathrm{sec}$, then the specific reaction rates have the values:

$$
\begin{aligned}
\text { at } 25^{\circ} \mathrm{C}: k & =1.30 \times 10^{-9} ; K=0.4 \\
\text { at } 100^{\circ} \mathrm{C}: k & =1.85 \times 10^{-8} ; K=0.3 .
\end{aligned}
$$

The apparent activation energies for $k$ and $K$ are 7.8 and $-1.1 \mathrm{kcal} / \mathrm{gmole}$. For potassium-feldspar the rate may also be expressed on the basis of gmoles of feldspar dissolved. The rate, $-r_{\mathrm{K} \text {.feld, has the units gmoles }}$ $\mathrm{K}$-feldspar $/ \mathrm{cm}^{2} / \mathrm{sec}$ (as based on the chemical formula) and the specific reaction rates are: $k=1.9 \times 10^{-9}$ and $4.5 \times 10^{-8}$ at 25 and $100^{\circ} \mathrm{C}$ respectively.

For sodium-feldspar the rate, $-r_{\text {Na-feld }}$, has the units gmoles Na-feldspar $/ \mathrm{cm}^{2} / \mathrm{sec}$ (as based on the chemical formula) and the specific reaction rates are: $k=1.8 \times 10^{-9}$ and $2.6 \times 10^{-8}$ at 25 and $100^{\circ} \mathrm{C}$ respectively.

Due to the lesser effect of $\mathrm{HCl}$ on the reaction rate the reported values of $a$ and $K$ can only be considered approximate.

The measured dissolution rates of the feldspars may most easily be compared with the dissolution rates found for the other minerals by calculating the rate of acid consumption. If for simplicity only hydrofluoric acid is assumed to be present, then the following rate law is obtained $\left(\mathrm{H}^{+} / \mathrm{HF} \sim 0.03\right):-r_{\mathrm{HF}}=k \quad(\mathrm{HF})^{b}$ gmoles $\mathrm{HF} / \mathrm{cm}^{2} / \mathrm{sec}$ for potassium-feldspar $k=3.8 \times 10^{-8}$ and $5.4 \times 10^{-7}$ at 25 and $100^{\circ} \mathrm{C}$ respectively.

These acid fluxes are substantially greater than those reported for the dissolution of vitreous silica and $\alpha$-quartz, but still much smaller than those found for the dissolution of dolomite and calcite.

\section{ANALYSIS OF THE SURFACE REACTION RATE LAW}

The present study investigates the dissolution in hydrofluoric-hydrochloric acid mixtures of two common members of the feldspar group under such conditions that the dissolution can be considered irreversible.

The feldspar group [12] consists of a series of minerals with nearly identical physical properties but quite different chemical compositions. The feldspars may be divided into two subgroups: the potassium feldspars (microcline) and the sodium-calcium feldspars (the plagioclase). The latter subgroup forms a continuous solution series from pure Na-feldspar (albite) to pure $\mathrm{Ca}$ feldspar (anorthite). The three-dimensional network of the feldspars consists of $\mathrm{SiO}_{4}{ }^{-}$and $\mathrm{AlO}_{4}{ }^{-}$tetrehedra as the building blocks. The negative charge of the network is balanced by the presence of cations such as $\mathrm{Na}^{+}, \mathrm{K}^{+}$, and $\mathrm{Ca}^{2+}$ in the interstices. The dissolution rates in hydrofluoric-hydrochloric acid mixtures of a feldspar from each of the two subgroups were measured.

In the presence of water[7] (or acid) the feldspars are unstable $[13,14]$ and will be transformed into hydrated aluminosilicates (solid) with the liberation of cations to the solution. Letting the chemical formula $Z \mathrm{AlSi}_{3} \mathrm{O}_{8}$ represent a feldspar, the reaction on the surface of the mineral may be expressed as:

$$
Z \mathrm{AlSi}_{3} \mathrm{O}_{8}+n \mathrm{H}_{3} \mathrm{O}^{+} \rightleftarrows\left(\mathrm{H}_{3} \mathrm{O}\right)_{n} \mathrm{AlSi}_{3} \mathrm{O}_{8}+Z^{+n}
$$

where $Z^{+n}$ represents cations such as $\mathrm{Na}^{+}, \mathrm{K}^{+}$or $\mathrm{Ca}^{2+}$ with charge $n$. In the feldspar structure (and other aluminosilicates) the covalent bonds between $\mathrm{Si}-\mathrm{O}$ and Al-O are much stronger than the ionic bonds between cations (such as $\mathrm{H}_{3} \mathrm{O}^{+}, \mathrm{Na}^{+}, \mathrm{K}^{+}$and $\mathrm{Ca}^{2+}$ ) and the lattice network. The latter bonds should therefore break much easier. This is exemplified by the reaction of dilute hydrochloric acid with the clays, kaolinite and montmorillonite $[15,16]$. The reversible exchange reactions between cations in the interstices of the lattice and cations in the solution are fast whereas the dissolution of the network is slow. The leaching of cations from the surface of the feldspars can therefore be considered fast as compared with the break-up of the lattice network. The dissolution rate and form of the rate laws for the two feldspars should then only show minor differences, which is what we observed.

The surfaces of $\alpha$-quartz[17] and silica[18] adsorb water strongly under the formation of hydroxyl groups (i.c. $\mathrm{SiOH}$ ) and we may expect a similar behavior on the surface of the feldspars (i.e. Si-OH and $\mathrm{Al}-\mathrm{OH}$ ). After leaching of the surface has removed cations such as $\mathrm{Na}^{+}$, $\mathrm{K}^{+}$and $\mathrm{Ca}^{2+}$, the network in the surface of the mineral will contain the following groupings: $\mathrm{Si}-\mathrm{OH}, \mathrm{Si}-\mathrm{O}-\mathrm{Si}$, $\mathrm{Si}-\mathrm{O}-\mathrm{Al}$ and $\mathrm{Al}-\mathrm{OH}$. When the network is being dissolved by the hydrofluoric-hydrochloric acid mixture, four bounds must be broken for the release of a silicon or aluminum to the solution. Since $\alpha$-quartz and vitreous silica dissolve much slower in the acid mixture than do the feldspars, the clays, hydrated silica, etc., it is reasonable to assume the breaking of the $\mathrm{Si}-\mathrm{O}$ bond in the $\mathrm{Si}-\mathrm{O}-\mathrm{Si}$ and $\mathrm{Si}-\mathrm{O}-\mathrm{Al}$ grouping to be rate limiting for the dissolution:

$$
\mathrm{Si}-\mathrm{O}-X+\mathrm{HF} \rightarrow X-\mathrm{OH}+\mathrm{SiF}
$$

where $X$ indicates either $\mathrm{Al}$ or $\mathrm{Si}$.

The dissolution rate is first order (or nearly first order) with respect to the $\mathrm{HF}$ concentration for $\alpha$-quartz, vitreous silica, and for the feldspars when the hydrofluoric acid concentration is less than 2.5 gmoles $/ 1$. This 
suggests the rate of reaction to be independent (or nearly independent) of the kind of bonding in which the three other bonds of silicon take part. The slightly different HF dependence of the dissolution rate of potassium feldspar may be a consequence of the weak interactions between the four reaction steps involved in the formation of $\mathrm{SiF}_{4}$.

When strong acids, such as hydrochloric acid, are present with the hydrofluoric acid, the rate of the dissolution of the two feldspars is increased markedly. The functionality of the rate law, eqn (21), indicates that two parallel reaction paths may exist for the dissolution process. Hydrogen ions are strongly adsorbed [19] on the surfaces of minerals such as $\alpha$-quartz [17], rutile [20] $\left(\mathrm{Al}_{2} \mathrm{O}_{3}\right)$, and clays because of the polar nature of the $\mathrm{Si}-\mathrm{O}$ and $\mathrm{Al}-\mathrm{O}$ bonds. In the lattice network oxygen will have a negative charge relative to silicon and aluminum, and hydrogen ions may therefore be adsorbed by the $\mathrm{Si}-\mathrm{O}-\mathrm{Si}$ and $\mathrm{Si}-\mathrm{O}-\mathrm{Al}$ group in the following manner:

$$
\mathrm{Si}-\mathrm{O}-X+\mathrm{H}^{+} \rightleftarrows X-(\mathrm{HO}) . . \mathrm{Si}^{+}
$$

The adsorbtion has the effect of decreasing the bond strength between silicon and oxygen; then the reaction of HF with the group should be considerably facilitated:

$$
\mathrm{X}-(\mathrm{HO}) . . \mathrm{Si}^{+}+\mathrm{HF} \rightarrow \mathrm{X}-\mathrm{OH}+\mathrm{SiF}+\mathrm{H}^{+} \text {. }
$$

Symbolically, the reaction of the hydrofluorichydrochloric acid mixture with the mineral surface may be expressed as:

$$
\begin{aligned}
A+B & \rightarrow \text { products } \\
A+C & \rightleftarrows A C \\
A C+B & \rightarrow \text { products }
\end{aligned}
$$

where $A$ is the number of $\rightarrow \mathrm{Si}-0-X \leftarrow$ sites per $\mathrm{cm}^{2}$

\section{$B$ represents the $\mathrm{HF}$ concentration \\ $C$ represents the $\mathrm{H}^{+}$concentration}

$A C$ is the number of $\left((X-\mathrm{OH}) \ldots \mathrm{Si}^{+}\right)$sites per $\mathrm{cm}^{2}$. The adsorption of $\mathrm{H}^{\dagger}$ on the mineral surface may best be described in terms of a Freundlich adsorption isotherm: [1]

$$
(A C)=K_{1}\left(A_{0}\right)(C)^{a}
$$

where $\left(A_{0}\right)$ is the total number of $A$ sites per $\mathrm{cm}^{2}$ and " $a$ " lies between zero and one; $0<a<1$. Although it is known primarily as an empirical adsorption isotherm, the Freundlich adsorption isotherm can be derived theoretically [21]. If the dissolution of the mineral surface is limited by the two parallel reactions (as given by eqns $(26-28)$ ), the rate of dissolution may be expressed as a sum of the individual reaction rates:

$$
r=k_{1}(A)(B)^{b}+k_{2}(A C)(B)^{b}
$$

This assumes the same HF dependence for both reactions. Substitution of eqn (29) yields:

$$
r=k_{1}(A)(B)^{b}+k_{2} K_{1}\left(A_{0}\right)(B)^{b}(C)^{a} .
$$

The two parallel reaction paths are competitive since a surface site takes part in both reactions and the number of sites is limited. The concentration of free sites is:

$$
(A)=\left(A_{0}\right)-(A C)=\left(A_{0}\right)\left(1-K_{1}(C)^{a}\right)
$$

which may be substituted into the rate expression:

$$
r=k\left(1+K(C)^{a}\right)(B)^{b}
$$

where $k=k_{1}\left(A_{0}\right)$

$$
K=\left(k_{2} / k_{1}-1\right) K_{1}
$$

The derived rate law, eqn (32) is identical to the one found by experiment, eqn (21). In the Freundlich adsorption isotherm, the parameter " $a$ " is a function of the temperature. However, owing to the limited data taken at different tempcratures, this dependency could not be determined. Similarly, the value of " $a$ " cannot be exactly one as was estimated for the sodium-feldspar from the limited experimental data.

Before closing our discussion we would like to suggest explanations of some previously reported data on the dissolution of $\alpha$-quartz in $\mathrm{HF}$ or mixtures of $\mathrm{HF}$ and $\mathrm{HCl}$. The experimental results of several investigators [22-24] show [8] that at HF concentrations less than 4 gmole/ 1 the slow dissolution reaction is probably first order in the HF concentration, whereas at higher concentrations (5-22 gmole/1), the order of the dissolution reaction increases with increasing HF concentration. The dissolution rate also increased when hydrochloric acid was present. In Fig. 5 we have replotted experimental data for the dissolution rate of $\alpha$-quartz in strong hydrofluoric acid solutions $(5-22$ gmole $/ 1)$ at $35^{\circ} \mathrm{C}$. A third-degree polynomial in the HF concentration was fitted to the data under the constraint that the reaction should be first order at low concentrations:

$$
-r=k_{1}\left(1+K_{2}(\mathrm{HF})+K_{3}(\mathrm{HF})^{2}\right)(\mathrm{HF})
$$

where $k_{1}=9.2 \times 10^{-9} \mathrm{~g} \mathrm{SiO}_{2} / \mathrm{cm}^{2} / \mathrm{sec} / \mathrm{HF}$ molarity

$$
\begin{aligned}
& K_{2}=0.04 ;(\text { gmoles } / 1)^{-1} \\
& K_{3}=0.005 ;(\text { gmoles } / 1)^{-2} .
\end{aligned}
$$

This rate law is in good agreement with the data determined for less concentrated solutions of hydrofluoric acid. Since hydrochloric acid increases the dissolution rate of $\alpha$-quartz we would also expect the strong, associated hydrofluoric acids $\left(\mathrm{H}_{n} \mathrm{~F}_{n}\right)$ to increase the rate. The functionality of eqn (33) suggests that a rate expression similar to the dissolution rate expression for the feldspars, eqn (21), may apply:

$$
-r=k\left(1+K\left(\mathrm{H}^{+}\right)\right)(\mathrm{HF}) .
$$

For simplicity, the exponent " $a$ " has been assumed to be equal to one; from the low HF-concentration experiments 


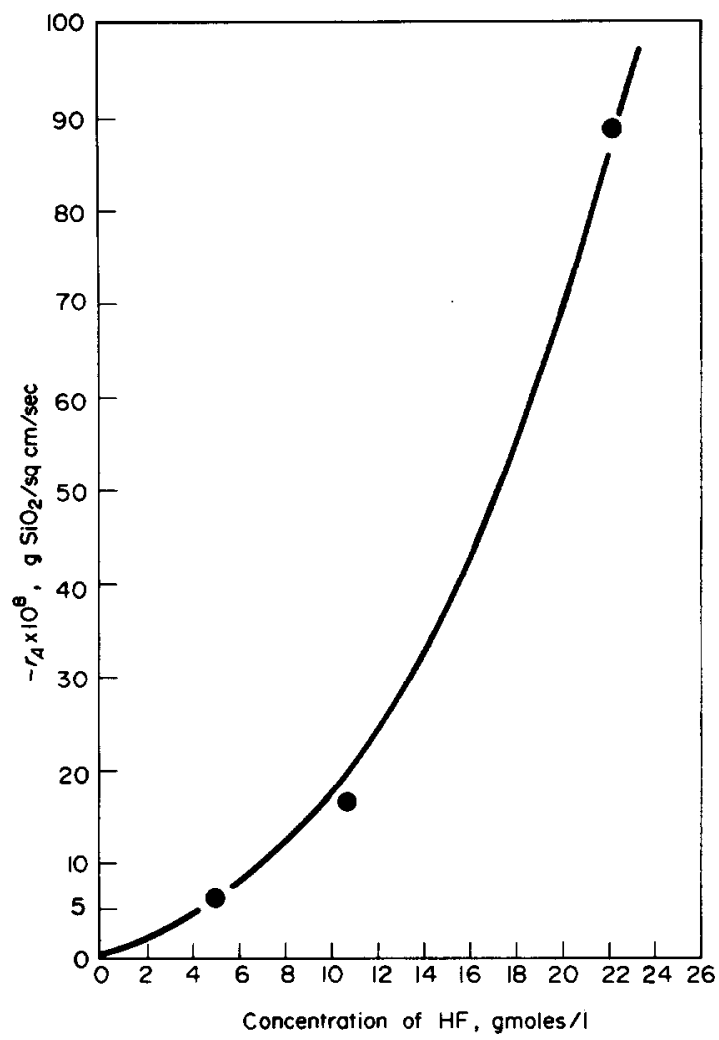

Fig. 5. Dissolution rate of $\alpha$-quartz at $35^{\circ} \mathrm{C}$ in HF.

we know that the exponent $b$ is equal to one. In pure hydrofiuoric acid the hydrogen ion concentration is approximately given by eqns (3) and (4)

$$
\begin{aligned}
\left(\mathrm{H}^{+}\right)^{2} & =\sum_{i=1}^{n} K_{R i}(\mathrm{HF})^{i} \\
\left(\mathrm{HF}^{o}\right) & =\sum_{i=1}^{n} i K_{R i} \frac{(\mathrm{HF})^{i}}{\left(\mathrm{H}^{+}\right)}
\end{aligned}
$$

and the rate expression becomes:

$$
-r=k\left(1+k\left(\sum_{i=1}^{n} K_{R i}(\mathrm{HF})^{i}\right)^{1 / 2}\right)(\mathrm{HF})
$$

For HF concentrations less than 10 gmoles/l this expression may be approximately by:

$$
\begin{aligned}
-r=k\left(1+K K_{R 2}^{1 / 2}(\mathrm{HF})\right)(\mathrm{HF}) & \\
& =k(1+0.047 K(\mathrm{HF}))(\mathrm{HF}) .
\end{aligned}
$$

If $K$ is the order of 0.8 , eqn (36) agrees remarkably well with eqn (33). It should be noted that for the dissolution of the feldspars we also found $K$ to be approximately equal to one. Further measurements of the dissolution rate of $\alpha$-quartz in hydrofluoric acid and hydroffuorichydrochloric acid mixtures are needed to decide if eqn (34) is valid general rate expression for the dissolution of $\alpha$-quartz.
SUMMARY

The dissolutions of a potassium-feldspar and a sodiumfeldspar in hydrofluoric-hydrochloric acid mixtures was studied with the aid of a rotating disk system. The composition of the acid mixture was varied from 0 to 2.5 gmoles $\mathrm{HF} / \mathrm{l}$ and 0 to 5.0 gmoles $\mathrm{HCl} / \mathrm{l}$. Under the conditions studied the dissolution rate is limited by the rate of reaction on the solid surface and is not affected by any resistance to mass transfer.

The rate law describing the dissolution of the two feldspars is

$$
-r_{A}=k\left(1+K(\mathrm{HCl})^{a}\right)(\mathrm{HF})^{b}
$$

where the rate, $-r_{A}$ is in gmoles feldspar $/ \mathrm{cm}^{2} / \mathrm{sec}$ and the concentration of $\mathrm{HCl}$ and $\mathrm{HF}$ are in gmoles/1. For the potassium-feldspar the parameters have the values: $a=0.4$ and $b=1.2$, at $25^{\circ} \mathrm{C}: k=1.9 \times 10^{-9}$ and $K=1.4$, at $100^{\circ} \mathrm{C}: k=4.5 \times 10^{-8}$ and $K=0.74$. The apparent activation energies of $k$ and $K$ are 9.3 and $-1.9 \mathrm{kcal} / \mathrm{gmoles}$ respectively. For the sodium-feldspars the parameters have the values: $a=1.0$ and $b=1 \cdot 0$, at $25^{\circ} \mathrm{C}: k=$ $1.8 \times 10^{-9}$ and $K=0.4$, at $100^{\circ} \mathrm{C}: k=2.6 \times 10^{-8}$ and $K=0.3$. The apparent activation energies of $k$ and $K$ are 7.8 and $-1 \cdot 1 \mathrm{kcal} / \mathrm{gmoles}$ respectively.

Analysis of the experiments suggests that the dissolution of a feldspar in hydrofluoric-hydrochloric acid mixtures is limited by the rate at which the hydrofluoric acid reacts with the solid surface. The strong effect of hydrochloric acid on the dissolution rate is a result of the adsorption of $\mathrm{H}^{+}$onto the mineral surface. The dissolution rates of the two feldspars are only slightly different as would be expected.

The available data on the dissolution of $\alpha$-quartz in hydrofluoric-hydrochloric acid mixtures suggest that a mechanism similar to that for feldspars governs the dissolution rate of $\alpha$-quartz.

\section{REFERENCES}

[1] Lund K., Fogler H. S. and McCune C. C., Chem. Engng Sci. 197328691.

[2] Lund K., Fogler H. S., McCune C. C. and Ault J. W., Chem. Engng Sci. 197530825.

[3] Ryss I. G., The Chemistry of Fluorine and its Inorganic Compounds. State Publishing House for Scientific, Technical and Chemical Literature, Moscow 1956. Atomic Energy Commision-USA Translation, February 1960, AEC-tr-3927 (pt. 1 and 2).

[4] Gordievskii A. V., Filippov E. L. and Kuprynin G. I., J. Anal. Chem. (USSR) 19631810.

[5] Ellis A. J., J. Chem. Soc. (London) 19634300.

[6] Kleboth K., Monatshefte f. Chemie 1968991177.

[7] Bondam J., Medd. Dansk Geol. Forening, København 196717 357.

[8] Lund K., On the Acidization of Sandstone, Ph.D. Thesis, University of Michigan (1974).

[9] Langmyhr F. J. and Paus P. E., Anal. Chim. Acta Vol. 43 397-408.

[10] Barth T. F. W., Feldspars. Wiley-Interscience, London (1969).

[11] Boomer D. R., McCune C. C. and Fogler H. S., Rev. Sci. Instr. 197243225.

[12] Mason B. M. and Berry L. G., Elements of Mineralogy. Freeman, San Francisco (1967). 
[13] Hess P. C., Amer. J. Sci. 1966264289.

[14] Hemley J. J., Amer. J. Sci. 1959257241.

[15] Turner R., Kinetic Studies of Acid Dissolution of montmorillonite and Kaolinite, Ph.D. Thesis, University of California, Davis (1964).

[16] Aldrich D. G. and Buchanan J. R., Soil Sci. Soc. Am. Proc. 195822281.

[17] Seifert H., Buhl R. and Seifert K. F., Koloid Zeitschrift 1955 141146.

[18] Hertl W. and Hair M. L., J. Phys. Chem. 1971752181.

[19] Sennett P. and Olivier J. P., I \& EC 19655733.
[20] Ahmed S. M. and Maksimov D., J. Colloid Interface Sci. 1969 2997.

[21] Hayward D. O. and Trapnell B. M. W., Chemisorption, 2nd edn. Butterworths, London (1964).

[22] Gatewood J. R., Hall B. E., Roberts L. D. and Lasater R. M., J. Pet. Tech. 1970693.

[23] Gatewood J. R., Preprint 25 Southwest Regional Meeting of ACS, Tulsa, Oklahoma, December 5, 1969.

[24] Heiman R. and Willgallis A., N. Jahrbuch f. Mineralogie, Monatshefte 1969145. 